\title{
ESTRATEGIAS DE PARTICIPACIÓN Y RELACIÓN CON EL PÚBLICO EN LAS ARTES ESCÉNICAS EN ESPAÑA A COMIENZOS DEL SIGLO XXI ${ }^{1}$
}

\author{
Oscar Cornago \\ Pesquisador do Centro de Humanidades do Conselho Superior de Investigações Científicas de Madri. \\ Doutor em Filosofia pela Universidad Autonoma de Madrid. \\ Pós-doutorado no Institut für Theaterwissenschaft da Freie Universität de Berlim \\ E-mail: revistacena@ufrgs.br
}

\section{STRATEGIES OF PARTICIPATION AND RELATIONSHIP WITH THE AUDIENCE IN THE PERFORMING ARTS IN SPAIN IN THE EARLY XXI CENTURY}

La conciencia de crisis de las democracias, acentuada en los periodos de recesión económica, obliga a revisar la idea de participación y la construcción colectiva de lo público. El objetivo de este artículo es el estudio de las formas de participación y la relación con el público en las artes escénicas en los últimas, así como su contextualización dentro de la evolución desde los años noventa. El análisis se centra en la trayectoria de Roger Bernat y Juan Domínguez y su recorrido del trabajo en primera persona a la construcción de un sujeto colectivo incorporado por el público.

\section{Palabras claves}

Artes escénicas. Participación. Democracia. Público. Siglo XXI
The sense of crisis of democracy, accentuated during periods of economic recession, agrees to review the idea of participation and collective construction of the audience. The aim of this paper is to study the forms of participation and the relationship with the audience in the performing arts in recent years, and its contextualization in the evolution since the nineties. The analysis focuses on the work of Roger Bernat and Juan Dominguez and its evolution from the first person to build a collective subject through the audience.

Keywords

Performing Arts. Participation. Audience. Democracy. XXIth century

\footnotetext{
1 Este artículo es resultado del proyecto de investigación «Las prácticas escénicas como forma social del conocimiento. Una aproximación crítica a la idea de participación en las culturas de las democracias» (HAR2014-57383-P) del Programa Estatal de Fomento de Investigación Científica y Técnica del Ministerio de Economía y Competitividad de España. El contenido es un desarrollo de temas que ya aparecieron en mi libro Ensayos de teoría escénica. Teatralidad, público y democracia, Madrid, Abada, 2015.
} 


\section{A modo de introducción:} el público, a escena!

El año 2008 puede servir como fecha de referencia. La crisis económica que estalla entonces sin previo aviso y aparentemente de forma inesperada termina de poner de manifiesto la distancia creciente que se había abierto entre las administraciones públicas y la economía a gran escala, por un lado, y la vida de las personas de pie y su pequeña economía. La realidad de los ciudadanos se había convertido en una irrealidad administrativa que no se seguía sosteniendo. La gente anónima, al margen de partidos políticos y líderes sociales, comienza a movilizarse. Los casos de corrupción de cargos públicos se multiplican. En el 2011 se inician las protestas sociales que dan lugar al movimiento $15 \mathrm{M}$, y que se terminan traduciendo en un panorama electoral, tres años después, en el que el bipartidismo que organizó la vida política desde la Transición se ve por primera vez seriamente cuestionado. La democracia trata de regenerarse.

Este mismo año se realizan dos obras escénicas, Dominio público, de Roger Bernat, y 300 personas y un oso, de Rosa Casado y Mike Brookes, que de manera orientativa pueden servir también para marcar un punto de inflexión, tanto en la trayectoria de sus creadores como en el ámbito escénico de investigación, hacia formatos en los que este público cada vez más invisible deja de ser parte la obra para ocupar el centro del espacio convirtiéndose ellos mismos en la obra. Esta utopía tantas veces repetida en el mundo del teatro se hace realidad a nivel formal: el público hace la obra. Sin establecer una relación directa causa efecto con el contexto económico, el panorama escénico al que nos vamos a referir responde a una misma necesidad, por parte de esa mayoría silenciosa que es el público, de alcanzar otro tipo de presencia.

Dominio público, cuyo título es ya de por sí significativo de esta nueva tendencia por la que iba a discurrir la producción posterior de Bernat, es probablemente la obra del Estado español que más veces se haya representado, sobre todo fuera de España, desde su estreno en el 2008. Seis años después pasa finalmente por Madrid y continúa en gira. En este sentido resulta también representativa de una demanda dentro de los circuitos internacionales de propuestas que proponen al público lugares diversos. Esto no resulta una novedad dentro de la historia de las artes en el siglo XX, pero sí los modos de afrontar esta nueva necesidad de confrontar al público consigo mismo.

Bernat pone en pie una suerte de coreografía social interpretada por los propios espectadores a través de los movimientos que realizan como respuesta a preguntas, aproximadamente unas cien, que escuchan por los auriculares que se les entrega al principio. Las respuestas dividen al público en varios grupos que desempeñan distintos roles. Preguntas sobre si ganan más o menos de 1000 euros al mes, el tipo de trabajo que realizan, si disponen de vivienda propia o viven de alquiler, el sitio donde fueron por última vez a veranear o lo que opinan sobre temas de actualidad, marcan los primeros pasos de esta coreografía que luego se va centrando en su propio desarrollo interno en relación a la ficción propuesta. Después de una historia de fusilamientos y operaciones de salvamento, la obra, que suele realizarse al aire libre, finaliza en una sala donde hay una maqueta que representa la situación que los propios espectadores han interpretado, como si todo aquello en lo que acabaran de parti- 
cipar fuera parte de un guión perfectamente calculado.

300 personas y un oso se hizo en Pontos, un pequeño pueblo de Girona, dentro del festival Mapa. La obra consiste en reunir una cantidad grande de personas en un claro de un bosque por la noche. Ese es el acontecimiento al que apunta, y el objetivo estético es hacerlo sensible en cuanto algo que está sucediendo en ese lugar y en ese preciso momento, del modo más sencillo, con la mínima mediación. Lo que se tiene que sentir no es la presencia del dispositivo, sino la de las personas, lo específico de ese espacio en el que se encuentran, que es ese, en ese momento, y no otro. Para ello se recurre, de una parte, al pasado de ese espacio natural, en el que alguna vez hubo osos, $y$, de otra, al deseo humano de las personas de llevarse recuerdos de los sitios por los que pasa. Una vez que el público llega al claro del bosque, después de ser recibidos por la creadora, se le explica que el evento al que van a asistir son ellos mismos, y que si desean llevarse un recuerdo de aquel momento se pueden hacer una foto con una persona vestida de oso que estará paseándose entre ellos. Eso es todo, una experiencia puntual, abierta y con algo de imprevisible, que forma parte de un proyecto más amplio, Something happening / snapshots, que consiste en intervenciones en el espacio público que ponen la memoria de los lugares en relación con el público que los ocupa durante la situación propuesta por la obra. Estas intervenciones suponen también un punto de inflexión en la evolución de Rosa Casado hacia lo que podríamos denominar una dramaturgia de lo público.

Como puede verse, estas obras comparten un espacio de creación comparable, pero las formas de articular la participación del público son casi opuestas. Frente al carácter puntualmente dirigido de las acciones en Dominio público, en 300 personas y un oso no pasa nada, o casi nada. El hecho de participar o no participar, que podía identificarse con la opción de hacerse la foto con el oso o no hacérsela, se convierte en una excusa casi anecdótica para dar lugar al verdadero acontecimiento de naturaleza más indefinida que es el hecho de estar ahí. Las reglas que organizan el encuentro, incluso haciéndose visibles, lo dejan tan abierto que el público queda sin saber exactamente qué hacer. Este no saber cómo seguir siendo público y al mismo tiempo dejar de serlo es el conflicto, de carácter distinto según las obras, sobre el que se crean estas dramaturgias motivadas por la necesidad de reinventar la dimensión pública de la sociedad como algo vivo y complejo. En palabras de Casado:

en estos trabajos lo que le da forma al evento, a lo que sucede, es lo que la gente decide hacer y cómo deciden o no sostener el momento [...] es hacer evidente las decisiones y las negociaciones que se dan en el momento, sean las que sean, tanto si es la respuesta que nos gustaría como si es otra que nunca imaginamos (2013, p. 29).

El objetivo de este ensayo es estudiar los modos de construir el hecho escénico a partir del trabajo con el público y la evolución que conduce hasta este tipo de propuestas, trazando un recorrido desde los años noventa, cuando se replantea la creación escénica desde la primera persona y el yo actúo, hasta la construcción de un sujeto colectivo, de un nosotros hacemos. Para ello vamos a seguir la producción de dos creadores, Roger Bernat y Juan Domínguez, que aunque vienen de ámbitos distintos, el teatro y la danza respec- 
tivamente, describen un recorrido comparable desde los años noventa en el desarrollo de formas de trabajo que se han acercado cada vez más al público.

Este movimiento se enmarca dentro de la tendencia de las artes visuales a la participación acentuada desde los años noventa (Groys 2008, Blanco 2001, Bishop 2012). A pesar de la diversidad de formas y denominaciones que han articulado este amplio espectro de la creación artística, tienen en común un fuerte carácter escénico motivado por un interés determinante por la apertura hacia lo público, la colaboración con colectivos no artísticos y la participación del público:

These projects are just a sample of the urge of artistic interest in participation and collaboration that has taken place since the early 1990s, and in a multitude of global locations. This expanded field of post- studio practices currently goes under a variety of names: socially engaged art, community- based art, experimental communities, dialogic art, littoral art, interventionist art, participatory art, collaborative art, contextual art and (most recently) social practice (Bishop 2011, p. 11).

Si bien los límites entre las artes visuales y las artes escénicas en este tipo de trabajos son a menudo difíciles de establecer, de ahí la denominación común de "artes vivas", los espacios y convenciones de presentación de unos y otros permite apuntar algunas diferencias más relacionada a veces con el imaginario cultural y la tradición artística que con su desarrollo práctico. Estas diferencias remiten, no ya a la presencia del intérprete, que es frecuente en la mayoría de estos proyectos en artes visuales, sino sobre todo a la presencia de un público convocado para encontrarse todos juntos en un espacio y durante un tiempo de- terminado. En el caso de las artes escénicas, a menudo no se trata de una obra expuesta para que el espectador participe de ella de forma puntual, sino que necesita la implicación de un público que se reúne durante el transcurso de la obra. La dimensión colectiva de este público resulta una diferencia cualitativa y un rasgo diferencial en el funcionamiento de las obras a las que nos vamos a referir.

\section{Del yo al nosotros:} hacia la construcción de un sujeto colectivo

En una coda añadida años después a "Las reglas del este juego", un texto del 2006 en el que Bernat expone la base teórica de estas obras de participación, se esboza un breve recorrido de su trayectoria según el tipo de actores con los que ha trabajado. Esta evolución es significativa para entender no solo la evolución del director catalán, sino la tendencia de las artes escénicas desde los años noventa. El punto de partida de este recorrido es el trabajo con actores, bailarines o performers, es decir, intérpretes con formación artística, no necesariamente teatral, a los que frecuentemente se les pedía trabajar desde su experiencia. No se trataba de que los actores actuasen y los bailarines bailasen, sino de que estuviesen en escena al lado de otros artistas y no artista abriendo un espacio de creación que se construía de modo colectivo sobre la experiencia compartida de ese proceso. La condición artística de cada uno, sin dejar de estar presente como instrumento de trabajo, pasaba a un segundo plano frente a la experiencia del momento y las relaciones que se iban generando. Desde ahí se propone un movimiento de renovación de la escena teatral. Es el momento 
en que Rodrigo García comienza a trabajar con la Carnicería Teatro en Madrid, a partir de los primeros años noventa, y la época de la General Eléctrica (1997-2001), impulsada por Roger Bernat y Tomás Aragay, un colectivo por el que pasaron numerosos creadores de la Barcelona de aquellos años. La acción se introduce en el ámbito teatral como un modo de reinventar la escena, la forma de estar en ella, de relacionarse con los textos, objetos e imágenes, y de dirigirse al público. En este contexto se suceden trabajos explícitamente autobiográficos que en algunos casos llegaron a ser parte de una tendencia fácilmente identificable. En $L a$, la, la, la, la, ya del 2004, Bernat presenta un autoretrato de un joven artista que por momento se sitúa entre la parodia y la provocación. La recurrencia a un yo a través de formas autobiográficas corría el peligro de cerrarse sobre sí mismo en una construcción tan irreal como la representación ficcional de la que se trataba de huir.

Más allá de clichés y modas artísticas, esta forma de estar en escena y dirigirse al públi$c o$, en la que los límites entre personaje y actor se solapan, responde a un giro más complejo que en algunos casos termina conduciendo a un trabajo colectivo del que público forma parte. Esa primera persona deja ver el vosotros al que se dirige, encarnado por el propio público y al que se interpela directamente como un modo de interrogarse por el sentido de ese encuentro. ¿Qué significa salir a escena, qué estamos haciendo aquí? Según los modos de situarse en este espacio de comunicación, la construcción del otro frente a que se realiza la acción va a ser distinta. Cuestionar el sentido de ese encuentro, replanteado a través de este eje relacional, está en la base de la producción de artistas que a la vuelta del 2000 alcanzarán un enorme reconocimiento internacional, como Rodrigo García o Angélica Liddell. La primera persona supone un lugar desde el que asumir la escena que no se reduce al uso de materiales autobiográficos o su conversión en un relato lineal, sino que implica un lugar distinto desde el que hacerse público y colocarse frente al público. Esta irrupción de una primera persona que no se limita a un nombre con una biografía, sino que es un espacio de experiencias y contradicciones que cuestiona los límites de esa identidad socialmente construida, es lo que causó polémica y hasta rechazo en el medio teatral más convencional, donde la función del actor estaba reducida a la de intérprete de los textos escritos por el autor dramático.

La reconsideración de la especificidad del artista desde su experiencia abrió las puertas a lo que Bernat señala como una segunda fase: el trabajo con actores no profesionales. Se da entrada así a una realidad social, igualmente en primera persona, pero que ya no es la de los creadores. Son mundos más lejanos como los de los taxistas en Rimuski (2008), los paquistaníes en Amnesia de fuga (2004), los niños en Tot és perfecte, los travestis en Das paradies experiment (2007) o personas concretas a las que se convoca para tener un encuentro puntual en Bona gent (2002). La tercera etapa sería el trabajo con el público, con un sector social no identificado previamente más que por el hecho de asistir a la obra. Se trata de un terreno más abierto, anónimo y heterogéneo, cuyo primer acercamiento en su caso sería Dominio público. El público deja de estar al otro lado del escenario.

Aunque estos tres momentos pueden sucederse cronológicamente, vistos desde hoy hay que plantearlos como opciones que se cruzan en la construcción de un sujeto colectivo, que se mueve entre la escena y la platea. Del yo 
se pasa al vosotros, y del vosotros al nosotros como pregunta última que plantea un medio artístico social por su modo de funcionamiento. El intérprete profesional actuando en primera persona, los actores no profesionales o el público hecho visible son distintas maneras de dar una dimensión social, más allá de lo artístico, al encuentro escénico que comienza cuando uno ya no es uno, sino una indeterminación que empieza por el más de uno. Es por esto que algunas de estas propuestas han sido identificadas con el teatro documental o teatro de lo real, de una realidad social mostrada en bruto como punto de partida del conflicto sobre el que se construye la obra.

Esta dimensión colectiva es el punto de partida para la construcción de un acontecimiento sobre unas reglas que no son otras que las reglas del juego social reducido a escala escénica. Como dice Bernat, las reglas siempre han estado ahí, para cualquier tipo de teatro -o encuentro social, podríamos añadir-, se trata de reconfigurarlas para que den voz a ese público que viene de fuera. A diferencia de otros modelos de teatro de participación, las dramatugias del público a las que remiten estas obras suprimen este lugar de enunciación previo reservado a los actores, con lo que queda un único espacio de enunciación colectivo, en la medida en que es ocupado por el público, en permanente proceso de construcción, ya que el público abandonará la obra sin que haya mediado un acuerdo explícito acerca de su identidad en ese espacio. Se despliega así un espacio de negociaciones que según las obras va a estar sujeto a reglas distintas, un ir haciéndonos nosotros como sujeto en construcción atravesado por imprevistos, reacciones espontáneas, emociones, rechazos, dudas $y$ atracciones que convierten un encuentro en un acontecimiento vivo. Sobre el público recae esta responsabilidad que le interpela, haciéndole visible en una escena que es el mismo como parte de un grupo. ¿Qué estoy haciendo aquí? y ¿Qué estamos haciendo aquí? son dos cuestiones que se interpelan de un modo recíproco.

La teatralidad ya no se proyecta desde un escenario ahora inexistente sobre un público disperso por todo el espacio, sino que se gira sobre sí misma, sobre su punto de partida, que es la mirada del espectador, tratando de cerrarse sobre ese lado menos definido y más imprevisible, pero también más determinante, por ese punto de fuga que es la mirada y la presencia del que viene de fuera, del otro, del extraño. Se hace coincidir el escenario con la platea y el espacio de actuación con el lugar de esa mirada. La teatralidad no tiene ya ningún otro objeto de representación que el propio público tratando de ser distinto a sí mismo. El mecanismo de distancias y tensiones entre actor y personaje característico de la teatralidad opera sobre ese público al que se invita a dejar de ser público sin dejar de serlo nunca del todo. El hecho mismo de mirar se convierte en una forma más de actuar. Se deja sentir la potencia social que reside incluso o sobre todo en acciones mínimas, como mirar, estar, dudar, no atreverse, emocionarse o ponerse en relación. Sin dejar de ser público, el público es también algo más. A ese algo más como materia prima de la construccion social se dirigen estas obras.

En comparación con otros modelos de participación desarrollados desde el ámbito teatral, como el movimiento de grupos de los años sesenta, o desde las artes, como el happening y la performance, en las que se rompe la distancia con el espectador invitándolo a participar 
del espacio de actuación, de la acción artística, ahora el público no abandona su lugar de público ni se reviste de una nueva condición, sino que actúa desde su condición indiferenciada como parte de un grupo, pero al mismo tiempo de forma individual, como asistentes a un evento que son ellos mismos participando de ese evento. La desaparición de la figura del actor, construida en otros tiempos con la imagen del vate, guía, agitador de conciencias, líder político o fígura mística, deja al público solo en escena sin otro horizonte al que oponerse o con el que identificarse que ellos mismos. Ese es el lugar sobre el que, a partir de los años noventa, se deja oír un interrogante no nuevo pero sí expresado desde un contexto distinto: ¿cómo volver a crear sujetos colectivos, cómo volver a plantear la acción desde un punto de vista no solo individual sino como grupo?

El horizonte de fondo ya no son las luchas contra las dictaduras o el modelo ideológico sostenido por los países socialistas, pero tampoco la construcción de una democracia que estaba por hacer, sino democracias liberales sólidamente construidas sobre un sistema económico que no dejan opción política ni sobre todo económica. La democracia es la única meta, pero también el propio enemigo. $\mathrm{A}$ falta de fórmulas definitivas, credos artísticos o programas políticos con una promesa segura, la repuesta pasa ahora por un entre todos que nunca a va a estar acabado ni admite identidades claras o definitivas, sino que se propone desde un proceso constante e inmediato de construcción.

Ese espacio indefinido se propone como condición de la acción colectiva. Todos somos espectadores y actores al mismo tiempo, pero el punto de partida es esto primero, la cualidad pública que tenemos todos en común. No hay nada que mirar, más que nosotros mismos en ese proceso de estar haciéndonos como sujeto social. La actuación deja de estar localizada en un actor o un grupo de actores aislado, sobre el que habría hecho recaer su peso tanto la teoría política como la tradición de la performance del siglo XX, para ser una responsabilidad compartida, un lugar móvil, frágil e intermitente que aparece y desaparece en la medida en que se activa.

3. Dispositivos de participación de Roger Bernat

Las obras de participación de Roger Bernat han convertido al público en soldados en un campo de batalla en Dominio público (2008), en los espectadores que no quieren ser en Pura coincidencia (2008), en bailarines de Pina Bausch en La consagración de la primavera (2010), en tribunal popular en un juicio en Please Continue: Hamlet (2011), en ciudadanos en un parlamento en Pendiente de votación (2012), en obreros de una fábrica tomada en Númax-Fagor-Plus (2013) o en manifestantes de una gran urbe latinoamericana a comienzos del 2014 en Desplazamiento de la Moneda. Estas son las ficciones, más o menos cercanas a la realidad de los participantes, pero no es desde ahí que se construye el conflicto escénico que pone en funcionamiento estos dispositivos. Esa es la excusa, la ficción o el contrato social que organiza el dispositivo artístico, pero su funcionamiento a nivel escénico tiene que ver con el modo de asumirlo. Participar o no participar, y cómo hacerlo es lo que genera el conflicto que anima estas obras. La obra hace visible el hecho mismo de la participación, y el placer, la incomodidad o la tensión que puede llegar a producir nace de sentirse uno mismo 
y sentir a los demás siendo parte de algo que no es solo uno mismo, ni siquiera un nosotros mismos, sino que nos engloba como parte de una situación que conocemos y desconocemos al mismo tiempo, conocemos sus reglas, pero desconocemos sus efectos.

Por un lado, está el tejido humano al que la obra da lugar, que es en sí mismo la obra, y por otro la obra en tanto que conjunto de reglas que generan esa situación que obliga a cada espectador a asumir una posición. A esta serie de reglas es a lo que denominamos dispositivo artístico. Los dispositivos operan sobre las personas que los activan, delimitando un espacio y un tiempo. Tiene un efecto de individualización. Los usuarios pasan a ser sujetos de una situación que no es la habitual, una situación marcada, con un funcionamiento propio que responde a la ficción creada por esas reglas. La ficción más recurrente, a nivel social, es la de consumidor como identidad del ciudadano, entendiendo el rol de espectador como una forma más de consumir. Los dispositivos artísticos se construyen en relación a los dispositivos sociales asumiendo una posición crítica que hace visible su funcionamiento llevándolo a un lugar distinto. Agamben (2011) denomina a esa base indiferenciada sobre la que opera el dispositivo el ser viviente o sustancia, y a la producción del dispositivo el sujeto, a lo que habría que añadir que ese sujeto es sujeto a esa ficción-dispositivo, que en el plano artístico es creada por la obra, pero que socialmente puede ser la familia, el ordenador, el metro o los servicios de sanidad.

La relación de poder que establece el dispositivo es uno de los elementos característicos en las obras de Bernat, cuestionando la aparente libertad de la que pueden hacer uso los participantes, o lo que Miessen denomina los abusos de la participación. Tanto Dominio público como las propuestas que le van a seguir hacen visible la maquinaria escénica como lugar de poder frente al cual el participante se tiene que situar. El nombre que adopta el colectivo que firma estos trabajos, FFF, the Friendly Face of Fascism, hace referencia a esta cara oscura de las formas de participación que a menudo se plantean como garantía de pluralidad. En Pura coincidencia, que siguió a Dominio público, no hicieron falta ni las reglas, porque el público solo tenía que hacer de público, seguir las convenciones habituales. La obra consistía en la proyección de imágenes del propio público grabadas mientras esperaba para entrar, durante el ingreso y finalmente mientras permanecían sentado observándose a sí mismo haciendo de público. Sobre las proyecciones aparece el texto de Peter Handke Insultos al público. El hecho de que este no supiera que se le iba a grabar garantizaba el conflicto al obligarle sin previo aviso a abandonar el anonimato que convencionalmente protege el lugar del espectador. La neutralidad del espectador, protegido en la oscuridad de la platea, se transforma en un espacio de tensiones a medida que la imagen de cada uno de ellos, de forma individualizada, empieza a proyectarse, apareciendo en actitudes y posturas no siempre tan respetables. El experimento de Handke, que suele ser totalmente inocuo cuando se realiza con un planteamiento dramático tradicional, alcanza toda su efectividad: la imagen como forma agresiva de individualización resulta más efectiva que la palabra.

A partir de ahí se sucede una serie de trabajos menos conflictivos, en los que se proponen modos de participación distintos, pero siempre mostrando abiertamente las reglas. Si en $\mathrm{La}$ 
consagración consiste, siguiendo el modelo de Dominio público, en realizar los movimientos que se indican por los auriculares para reconstruir la coreografía que Pina Bausch hizo en 1969 de La consagración de la primavera, en Please continue: Hamlet se trata de condenar o salvar al acusado, emitiendo un juicio que al final no se llega a pronunciar, en Pendiente de votación, en organizarse como parlamento a través de una serie de votaciones que comienzan siendo individuales y luego van siendo por grupos cada vez mayores, y en Númax-Fagor-Plus en leer los subtítulos que corresponden, primero, a los diálogos de una asamblea de obreros de una fábrica tomada, en el caso de la película de Joaquím Jorda Númax presenta, y luego al encuentro que para este mismo proyecto se hizo con los extrabajadores de la cooperativa Fagor.

Obviamente, las formas de construcción de estas obras, en relación a sus respectivas ficciones, dan lugar a mundos escénicos muy distintos. Aunque en todos los casos, estos dispositivos se sitúan entre el experimento social y el juego colectivo. Esta es la diferencia entre un dispositivo social y un dispositivo estético, donde la eficacia no radica en la identificación con el papel, sino en la situación a la que da lugar y las actitudes, conflictos y emociones que se desarrollan sorteando la rigidez con la que se imponen las reglas. Es en esos espacios sobrantes, cuando la distancia entre ser viviente y subjetividad cuestiona los límites de esta última, que la obra se hace más viva.

En este sentido, Desplazamiento del Palacio de la Moneda, presentada en Santiago de Chile, marca un salto cualitativo, ya que su activación no se realiza únicamente en el transcurso de la obra, sino que empieza varias semanas antes cuando se inician los encuentros y con- versaciones con los posibles participantes, lo que ya se había anticipado en el caso de los extrabajadores de Fagor. Este trabajo previo es ya en cierto modo resultado de un dispositivo cuya forma final hay que ir negociando con unos participantes que serán también público, pero que no son solamente público. En el caso del Desplazamiento es una manifestación que recorre las calles de Santiago durante dos días llevando a hombros una maqueta del Palacio de la Moneda. Las asociaciones encargadas de llevarla leen al final del tramo que tienen asignado, de unos 300 metros, sus reivindicaciones desde un balcón improvisado que se coloca en el centro de la maqueta del Palacio de Gobierno de Chile. En la marcha participaron más de 30 colectivos.

Ya no se trata de un público que viene de fuera y se pone en relación con la ficción propuesta por el dispositivo, sino de los actores sociales convertidos en participantes de esa ficción que se superpone ahora de un modo inquietante con el contexto social que representan. La actitud frente a la propuesta, que implicaba llevar sobre los hombros el símbolo del poder nacional, supone para los colectivos tomar una decisión que de forma más clara que en otros casos va más allá de lo escénico. Tanto para el público que pertenecía a las asociaciones involucradas como para el otro público, el del Festival de Santiago a Mil donde se hizo la obra, el evento tenía un carácter social que iba más allá de su condición artística sin que una cosa excluyera la otra. Lo artístico y lo social conseguían superponerse sin que fuera posible determinar donde empieza el público de la obra y dónde los participantes de la popular marcha en defensa de aquellas reivindicaciones que se fueron leyendo al amparo de un poder político, que podría hacerse 
extensible al poder artístico, simbólicamente trasladado a los márgenes de la ciudad.

\section{Coreografías del público: Juan Domínguez}

cambiar la relación con el espectador, la implicación de este, acceder al efecto y a la repercusión que el propio trabajo tiene en el espectador, implicarme en la realidad de esos efectos, en las esferas de quienes finalmente los experimentan, y dejar de relacionarme únicamente con la esfera del que decide qué es lo adecuado para el espectador (Domínguez, 2004, p. 106)

A raíz de la primera temporada de La serie escénica, Clean Room, realizada por primera vez en 2013, Juan Domínguez insiste en cambiar la relación con el espectador, lo que suponía no solo variar la posición de este frente a la obra, sino también la suya propia como creador, llevando la creación a un espacio más inestable, más frágil y menos dirigido a través de propuestas abiertas donde, como dice en la cita anterior, no sea únicamente el artista el que decide lo que va a pasar. Este proyecto está inspirado en el modelo, más que narrativo habría que decir relacional, de las series de televisión. Traer para la escena el tipo de vinculación que las series consiguen con su público, la fidelidad que generan, las expectativas que despiertan, el mundo al que dan lugar más allá de la serie, que pasen a formar parte de las conversaciones y la vida de sus seguidores, son las ideas que están en la base de este proyecto. La obra no se centra, sin embargo, en el producto que se le va a ofrecer al público, sino que muy al contrario de lo que es lo habitual en estas producciones, Clean Room se sitúa directamente del lado de los espectadores y se hace con ellos. El giro de la escena sobre la platea se transforma en este caso en una serie protagonizada por el público. El efecto de responsabilidad que este asume frente a la obra se traduce ahora también en una demanda de fidelidad. La propuesta está dividida en seis capítulos que se realizan a lo largo de tres días. Cada día se hacen dos dejando entre medias un día libre. En el caso de Madrid, donde se realizó en el 2014 en La Casa Encendida, el aforo era de ochenta personas y no se permitía sacar entradas para un capítulo por separado. La entrada era para toda la serie, de modo que se podía dejar de asistir, pero no se podía empezar por la mitad. Se pedía a los asistentes que se comprometieran a acudir a todos los capítulos, de modo que fueran las mismas personas las que se se encuentrasen en cada episodio, un elemento fundamental puesto que es a partir de las expectativas creadas, de la experiencia compartida y el irse viendo una y otra vez, de las relaciones y amistades que se van creando que se hace finalmente la serie.

De modo comparable a ese grado cero propuesto por Casado y Brookes en 300 personas y un osos, cada capítulo se construye sobre la situación real en la que se encuentra el público y en la que se interviene de forma más o menos evidente según los casos. El primer capítulo se desarrolla en el hall de entrada. Durante toda la hora, que aproximadamente dura cada uno, la situación que se teatralizada es la de estar esperando para entrar. En ese espacio se produce una serie de intervenciones, primero de responsables del centro cultural y personas del público vinculadas a ese centro, hasta que en último lugar interviene Juan Domínguez dando por finalizado el primer capítulo e invitando al público a entrar al segundo. Las intervenciones, que en principio parecen no ser parte 
de la obra, se hacen cada vez más delirantes, precipitándose a un ritmo acelerado. El público toma conciencia de la situación, se relaja y disfruta del momento lleno de golpes de comicidad. El segundo capítulo cambia radicalmente de tono. Se trata de una sala a oscuras donde se oye una música tenue. Una voz cálida evoca lugares lejanos, aromas y sensaciones, invitando a seguirla en su viaje, "jugamos todos a la vez, pero es un juego individual" 1 . Un viaje interior que se rompe a la salida con un concierto de rock.

El tercer episodio se demora 15 minutos en empezar. El público se reconoce de la vez anterior y comienza a sospechar que el siguiente capítulo ya ha empezado. Estar esperando el siguiente episodio, como en el caso de las series, es ya parte del mundo creado por la obra. Las dos entregas siguientes proponen situaciones de relación más próximas, primero cara a cara, sentados en sillas colocadas frente a frente, y con la guía de la misma voz en off ahora con un tono más intimidante haciendo preguntas sobre uno mismo y sobre el que está delante. Luego se pasan a mesas para varias personas donde se les sirve no solo vino y pequeños canapés, sino constantes tarjetas donde vuelven las preguntas acerca de lo que están viviendo. La conversación entre los ocupantes de cada mesa sobre lo que está pasando es inevitable. De final de fiesta nuevamente música, baile y un intercambio de regalos que en el capítulo anterior se les animó a traer. Funcionarán como ese recuerdo que al igual que proponían Brookes y Casado, las

1 En el blog de Perro Paco se encuentra una detallada descripción de cada uno de los capítulos firmada por Guri Petre, de la que toma las referencias. http://www.tea-tron.com/ perropaco/blog/2014/11/10/clean-room-temporada-1-episodios-1-y-2/ personas tienden a llevarse de un sitio donde han vivido una experiencia. En la foto de familia con la que se cierra la temporada aparecerá cada uno con su regalo. Los dos últimos episodios se hacen a medio día, con la claridad de la luz, una nueva situación para un público que se ya se había acostumbrado a la noche, la oscuridad de la sala y los ambientes cerrados. Tras una sucesión interminable de brindis por todo lo imaginable, guiada por la voz, que ahora toma cuerpo, el grupo hace un recorrido por la ciudad, primero andando, luego en autocar y finalmente en teleférico. La ciudad se convierte en un escenario improvisado en el que podría reconocerse cualquiera de ellos. Todos son actores, y todos podrían ser también ese público que va por la calle. Los lugares son intercambiables y los límites se confunden.

Si en los años sesenta Peter Brook propuso el espacio vacío para reinventar el arte del actor, a comienzos del siglo XXI, tras una aventura que terminó convirtiendo todo en espectáculo, Domínguez propone este espacio limpio como una forma de reinventar el difícil arte de ser público en un medio donde todo parece estar hecho, acabado, listo para su consumo. La historia no tiene marcha atrás, es inútil no reconocer la condición compartida de actores y de públicos. Ser espectador no sirve ya de excusa para esquivar las responsabilidades, ni tampoco los placeres, del juego social.

La trayectoria de Juan Domínguez hasta llegar a La serie describe un recorrido comparable en cierto sentido con el propuesto por Bernat. Ahora es el el bailarín, en lugar del actor, el que empieza a comienzos de los dos mil a plantearse el sentido de trabajar delante de un público. Ahí comienza su obra propia al margen de las compañías con las que había bailado hasta entonces. The taste is mine (2002) 
es una obra todavía de transición, heredera del conceptualismo de la danza de los noventa, aunque ya las gradas dividían al público en dos grupos situados frente a frente, y provistos de auriculares por los que se oía músicas distintas según los lados. Desde entonces hasta La serie, que podríamos subitular como The taste is ours, son más de diez años proponiendo maneras distintas de presentarse frente al público y relacionarse con él.

Como explica él mismo (Domínguez 2008, p. 115), cuando empezó a bailar en un país en el que todavía quedaba algo de aquella energía de una democracia recién estrenada en la que todo estaba por hacer, la presencia del público ocupaba un lugar secundario. Lo que tenía que pasar, pasaba en el escenario. En la calle sucedían suficientes cosas como para ocuparse de la salud social del público. También en el mundo de la nueva danza en Madrid en esos últimos años ochenta y principio de los noventa estaba todo por hacer. Lo importante era el trabajo como intérprete dentro de la compañía y la realización de la obra. Es a finales de los noventa y sobre todo ya en los dos mil cuandose hace más urgente, al igual que va a ocurrir en la escena teatral, preguntas acerca de la cualidad no ya formal sino social de la danza. Es como respuesta a esta pregunta que distintos espacios artísticos confluyen en ese espacio común de las denominadas artes vivas.

A The taste is mine le seguirá Todos los buenos espías tienen mi edad (2002), una autobiografía ficcional que supone una ruptura radical con el trabajo anterior. Domínguez aparece vestido con traje y camisa, sentado detrás de una mesa, de la que solo se levanta al final de la obra para ponerse una careta de él mismo con el aspecto que tendría a los 65 años. Toda la obra consiste en la proyección de diapositi- vas con texto que él va pasando por medio de unas cartulinas y un circuito cerrado de vídeo. La coreografía de los cuerpos se transforma en una coreografía de ideas, pensamientos desordenados, ficciones, deseos e imaginaciones calenturientas que a la vuelta de los años terminarán sosteniendo esa coreografía del público que es Clean Room. El espectador dejará de ser ese extraño que viene de fuera, ve la obra y se va, para convertirse en colaborador de un proyecto de público hecho en común y desde el deseo. Si en obra anteriores como The Application (2005), Shichimi Togarashi (2006) o Ya llegan los personajes (2011), los compañeros de viaje habían sido otros artistas, ahora es el público al que se le invita a ponerse en relación, descolocarse, perderse, reinventarse.

5. Conclusión: representación, acción, situación

"Ser tan solo espectadores es una presunción intolerable".Con esta idea resume el cronista de La Serie, Guri Petre (2014), su experiencia. Nadie es solamente espectador, ni tampoco solamente consumidor. Pero también se podría dar la vuelta a la afirmación, nadie es solamente actor, lo cual podría ser calificado también de presunción intolerable. Igual que ha ocurrido con otras funciones artísticas, como la del personaje, autor dramático, bailarín, director o coreógrafo, la identidad del espectador, a imagen de la del ciudadano, adquiere unos límites porosos necesarios para abrirse a otros lenguajes que proponen nuevas formas de habitar el espacio público. La conciencia de crisis de las democracias, acentuada en los periodos de recesión económica, obliga a revisar la idea de participación y la construcción colectiva de 
lo público. La expresión de esta necesidad en el campo de las artes ha llevado, por un lado, a la focalización del público como parte activa y visible del hecho artístico, y por otro al desarrollo de una ilimitada variedad de formas que cuestionan las convenciones, tanto artísticas como sociales, que identifican al público con la figura del consumidor, caracterizada por su pasividad y facilidad para ser manipulado.

Representación, acción y situación pueden entenderse como tres categorías artísticas que se han sucedido cronológicamente y que hoy conviven bajo el predominio de esta última. Si la acción nace como reacción a la representación, la situación se plantea en otro nivel, no es una respuesta a la acción, sino su desarrollo a nivel colectivo y más allá de la escena de actuación. Tampoco es un producto ya de las vanguardias, sino de un momento posterior en el que el crítica de la representación deja de ser el eje frente al cual definirse. No se trata de establecer mayor o menor distancia con el público, porque este forma parte, desde antes de que comience la obra, de la situación dentro de la que esta tiene lugar. La obra, como el público, pasan a ser dos elementos más de un conjunto de funciones heterogénas, como el espacio en el que se trabaja, la ciudad donde se hace la obra, las formas de producción, la memoria del lugar o el contexto económico, sobre las que opera el dispositivo artístico. Las formas de relacionarse con el público y articular este espacio quedan abiertas a una multitud de opciones que ya no se miden con el baremo de más o menos representacional. El objetivo de la situación no es alcanzar algún tipo de unidad con el público. Las distancias, la representación y los conflictos están asumido como factores inevitables y necesarios, no se trata de eliminarlos, sino de colocarse frente a ellos.

Si la representación se despliega temporalmente, y la acción enfatiza un momento puntual, rompiendo la linealidad de la representación, la situación se despliega en un tiempo suspendido a lo largo de un presente en el que conviven elementos a distintos niveles que comparten un mismo espacio. La situación es siempre algo más que la obra. Supone una superación del campo artístico a través del carácter social que implica esa convivencia de elementos. Si la representación trata de ir más allá de lo artístico a través del efecto de su recepción por parte del público, y la acción apunta al campo de la experiencia como puerta de salida del medio artístico, en el caso de la situación es la dimensión plural y colectiva la que cumple esta promesa histórica del arte de no ser solamente arte.

El público es el punto ciego del dispositivo teatral, pero también es el punto ciego de las democracias. La desacreditación de lo público como una abstracción puesta al servicio de intereses ajenos es un capítulo más de una crisis de la representación aceptada ya como fenómeno originario de la contemporaneidad. El objetivo no es salvarse de la representación, sino adoptar una postura frente a una situación inevitable. El fraude de los mecanismos de representación ha conducido las prácticas escénicas a la búsqueda de otras maneras de producirse públicamente y en relación directa con el público. La construcción de una idea de grupo a menudo identificada con la utopía de la comunidad ha sido una constante de la escena moderna, lo significativo es que esta búsqueda vuelva a plantearse a comienzos del siglo XXI no desde un principo estético o ideológico, sino desde una voluntad social que se levanta desde lo más cotidiano, indife- 
renciado y anónimo que tiene la condición de público. Se trata de experimentar y recuperar la capacidad social desde ese lugar de desconocimiento que se muestra abiertamente sin protegerse en una identidad determinada, ya sea la del espectador, público, artista o ciudadano. Tomar conciencia de nuestra capacidad como público sin abadonar por ello este lugar común, justamente por eso, porque es lo que tenemos en común, es el punto de llegada de estas dramaturgias del público.

Referencias

Agamben, G. (2011). ¿Qué es un dispositivo? Sociológica. Barcelona, $n^{\circ} 73$, p. 249-264. Disponible en http://www.revistasociologica.com. $\mathrm{mx} / \mathrm{pdf} / 7310 . \mathrm{pdf}$

Bernat, R. (2010). Las reglas de este juego. En Cornago, Ó. (ed.). Utopías de la proximidad en el contexto de la globalización. La creación escénica en Iberoamérica (p. 307-314). Cuenca: Universidad de Castilla-La Mancha. Otra versión de este trabajo disponible en http://rogerbernat.info/txts/

Bishop, C. (2012). Artificial hells: participatory art and the politics of spectatorship. London: Verso.

Blanco, P. (ed.). (2001). Modos de hacer. Arte crítico, esfera pública y acción directa. Salamanca, Universidad de Salamanca.

Casado, R., Brookes, M., (2013). Y si el acontecimiento somos nosotros. En Cornago, Ó. Manual de emergencia para prácticas escénicas. Comunidad y economías de la precariedad ( $\mathrm{p}$.
45-64). Madrid: Con tinta me tienes. Disponible en http://artesescenicas.uclm.es/index.php?sec $=$ artis\&id $=336$

Domínguez, J. (2008). Fragmentos de conversaciones. En Cornago, Ó. Éticas del cuerpo. Juan Domínguez, Marta Galán, Fernando Renjifo (p. 114-128). Madrid: Fundamentos. Disponible en http://artesescenicas.uclm.es/index. php?sec=texto\&id $=164$

Domínguez, J. (2013). Es fundamental hacernos sensibles, hacernos porosos, implicarnos. En Cornago, Ó. Manual de emergencia para prácticas escénicas. Comunidad y economías de la precariedad (p. 106-122). Madrid: Con tinta me tienes. Disponible en http://artesescenicas.uclm.es/index.php?sec=texto\&id=397

Groys, B. (2008). A genealogy of participatory art. En Frieling, Rudolf (ed.). The art of participation. 1950 to now (p. 18-31). Londres/Nueva York: San Francisco Museum of Modern Art/ Thames \& Hundson.

Miessen, Markus (2014). La pesadilla de la participación, (Barcelona: dpr).

Petri, G. (2014). Clean Room. Temporada 1. Blog Perro Paco. http://www.tea-tron.com/ perropaco/blog/2014/11/15/clean-room-temporada-1-episodios-5-y-6/ Consultado el 22 de febrero de 2014.

Recebido em: 16/09/2016 Aprovado em: 18/09/2016 